\title{
Introducing Interdisciplinary English Language Classroom in Bangladesh: An Assessment
}

\author{
Barnali Talukder* \\ Lecturer in English, Faculty of Arts \& Humanities, University of Chittagong, Chattogram - 4331, Bangladesh \\ *Corresponding Author: Barnali Talukder, Lecturer in English, Faculty of Arts \& Humanities, \\ University of Chittagong, Chattogram - 4331, Bangladesh
}

\begin{abstract}
Disciplinary knowledge aims at expertise while interdisciplinary education drives learners to brainstorm from multiple perspectives. In other words, interdisciplinary education reinforces the idea of salad bowl that preserves multiplicity of knowledge in a single pot. In Bangladesh, therefore, where learning English has an unparallel importance, exploring other branches of knowledge confronts the challenge of time and effort management at times. Learning English is essential to communicate with the world, but learning it combining with other disciplines can be more effective. To assess the practicality of implementing an interdisciplinary English language classroom, the study here has focused on Grammar Translation Method (GTM) and Communicative Language Teaching (CLT), mostly applied methods in Bangladesh's classrooms, among other methods and approaches of foreign language learning. The study, however, has tried to transform certain activities from above-mentioned methods and later combine them with questions from the discipline of History to observe whether such combination is possible or not. Resultantly, it appears that the selected activities can successfully be transformed into interdisciplinary format which compels the study to recommend adopting an interdisciplinary method in Bangladesh's English language classrooms on a short scale initially.
\end{abstract}

Keywords: English, History, Interdisciplinary, Bangladesh, GTM, CLT

\section{INTRODUCTION}

Yoriko Lida (2007) in a study defines the method of multidisciplinary approach to teach a foreign language claiming "the interdisciplinary curriculum is an approach using more than one discipline to examine a central theme, issue, problem, topic and so on. For instance, when students learn the English language, they study not only the language, but the English-speaking history and culture." However, in the context of Bangladesh, changing an entire curriculum all of a sudden to dispatch knowledge about other disciplines along with sharpening language skill might be difficult, but it demands future research and evaluation as English possesses a vast space in the curriculum. If properly analyzed, it is found that the socio-cultural history of English, in Indian subcontinent, encroaching on the national curriculum of the country has "their roots in the colonial past" with the use of English "in political discourse" "to communicate with the elites of the region" (Rahman et al., 2019). Following the integration of English into national curriculum, "during the Pakistani regime, English continued to be widely used as a recognized state language with the status of second language" in earlier East Pakistan, present Bangladesh. After independence, Bangladesh adopted "article 3" in "1972" that legalized "the use of English in the official, social and educational spectrums" of the country. Such a long history of English gradually entering the social, cultural and academic domain in Bangladesh eventually necessitates the importance of design, implementation and investment regarding the training and use of English (Rahman et al., 2019). "With over 30 million students learning English as a compulsory subject from grade 1 in the different streams of pre-tertiary education, Bangladesh has one of the largest English learning populations in the world", according to M. Obaidul Hamid and Elizabeth J. Erling (2016). This huge number of learners who are spending much time on learning English are primarily relying on language-based classroom as the government of Bangladesh has introduced Communicative English Teaching in 1996 that is implemented from class 6 to class 12 (Chowdhury \& Kabir, 2014). Considering the number of learners as well as the amount of time involved in English language learning, it can be suggested that Bangladesh needs a multifunctioning method to foster the acquisition of language skills and disciplinary knowledge at the 
same time. The prominent methods existent in Bangladesh in English Language Teaching are Grammar Translation Method (GTM) and Communicative Language Teaching (CLT) regarding which Mohammad Mosiur Rahman and Dr. Ambigapathy Pandian trace the history how in mid1990s, traditional GTM experiences a replacement with CLT in order to initiate an effective language learning (Rahman \& Pandian, 2018). However, the study later has introduced all of the methods prevalent in foreign language teaching in brief. It is here to mention that enhancing the role of language classrooms in distributing knowledge can be a dimensional change in the context of language learning in Bangladesh. For this purpose, introducing interdisciplinary teaching method in English language education initially narrowly can be implemented to assess the practicality and effectiveness of an integrated learning system. The study, therefore, has argued for introducing an interdisciplinary teaching method in Bangladesh to examine whether such interdisciplinary method of learning a foreign language brings better utilization of time and money invested in English teaching and learning. It is to be mentioned here that the reflection here in the study does not argue for abolishing disciplinary English language instruction system altogether - instead it is suggested to think about the initiation of interdisciplinary English language learning limitedly at any level of education so that the effectiveness of it can be evaluated accordingly. The study here has not employed any extensive survey to reach the proposed end, rather it has theoretically framed few ways to integrate different disciplines to avoid additional effort, time and expenditure English as a language requires to be learned. To do that, two activities from the two most vastly used methods - the GTM and the CLT have been combined with the discipline of History to frame few interdisciplinary activities. In conclusion, it is found that the selected activities have successfully assumed the frame of interdisciplinary study format. However, it is yet to be researched whether the methods and approaches can wholly be made interdisciplinary and can be employed in all sectors of English language education.

\section{LITERATURE REVIEW}

In the article "An Interdisciplinary Approach to Teaching Academic Speaking Skills," the researcher Santosh Kumar Mahapatra (2014) shows how he applies content-based approach to teaching academic presentation skill to engineering students. The author concludes that the entry level students who have better understanding of English respond well, but the low-standard students get in a trouble in handling duel challenge of sharpening skill and focusing on content. Cynthia Lee (2008), in a study titled "Interdisciplinary collaboration in English language teaching: some observations from subject teachers' reflections," shows a collaboration between English language instructor and subject teacher that results in a several findings including the high communication cost such venture requires. The author suggests that English language instructor is supposed to go deep into the subject knowledge that can make an effective collaboration.

\section{RATIONALE OF THE STUDY}

Bangladesh once belonged to British colony that formulated education policy to further their domination. In spite of being a separate nation at present, she has not been able to remove her colonial legacy (Chowdhury \& Kabir. 2014). "Currently English is taught as a compulsory subject from classes 1 to 12 in the national curriculum. With over 17 million children learning English, Bangladesh boasts one of the largest primary second language (L2) populations in the world" (Hamid \& Honan [2012], p, 141) (Chowdhury \& Kabir, 2014). It is noticeable that such a large number of learners are employing 12 years in learning a foreign language and it undoubtedly requires the investment of good span of time. To better utilize this time, content-based teaching can contribute to both language and subject learning.

\section{Methodology}

The study here has attempted some activities from GTM and CLT. These activities have been chosen arbitrarily, not maintaining any primary, secondary and higher level standard. In order to experiment the possibility of transforming traditional activities of GTM and CLT into interdisciplinary format, the study has chosen History to combine language activities with those of History. Although, in Bangladesh, GTM and CLT are prominently in practice, the study has brought all the approaches and methods in use of teaching foreign language to the light so that a brief overview of the available practices gets an introduction. Therefore, two activities from each of GTM and CLT have been taken from a referred source and translated into interdisciplinary pattern. Instead of attempting a practical survey, the study has confined its area of research to exploring the probability whether an interdisciplinary language format is practically applicable or not. 


\section{APPROACHES ANd Methods of Foreign LANguage ACQUisition}

There are a substantial number of methods available in disseminating foreign language learning and teaching. Among these, several ones have achieved the recognition to be most effective, if enlisted, that stand: the Grammar-Translation Method, the Direct Method, Situational Language Teaching, Audiolingual Method, the Communicative Method, Total Physical Response, the Silent Way etcetera. The ongoing discussion requires reflections on these methods and approaches stated above. It begins with the teaching of Latin and Greek of which Latin, in the past, "was taught by means of what has been called the classical method: focus on grammatical rules, memorization of vocabulary and of various declensions and conjugations, translation of texts, doing written exercises' that in the nineteenth century becomes the Grammar Translation Method" (Brown, 2000, p. 15). The GrammarTranslation Method, therefore, includes the study of grammar, vocabulary and translation which requires transmutation of language into another. Around the same time, another approach, the Direct Method, starts developing a methodology of which Gouin is the precursor and which believes that "teachers must encourage direct and spontaneous use of the foreign language in the classroom" (Richards \& Rodgers, 1999, p. 9). The Direct Method inspires the learners to induce grammar rules on their own, attends speaking with focus on pronunciation and use known words to reach the unknown with the help of mime, demonstration, and pictures (Richards \&Rodgers, 1999, p.9). Situation Language Teaching or the Oral Approach is the next one in this regard where "the meaning of words or structures is not to be given through explanation in either the native tongue or the target language but is to be induced from the way the form is used in a situation" (Richards \& Rodgers, 1999, p. 36). In this approach instead of explaining general rules of language use to the learners, situation is created to naturally acclimate them to suitable utterances. The Audiolingual Method is another such approach that prioritizes structure over meaning. It is to mention that "Audiolingualism is primarily an oral approach to language teaching" and "the process of teaching involves extensive oral instruction" in the target language (Richards \& Rodgers, 1999, p. 57). The Communicative approach is also implemented in foreign language classroom where "language teaching starts from a theory of language as communication," "the goal" of which "is to develop "communicative competence" (Richards \& Rodgers, 1999, p. 69). In this method, "contextualization is a basic premise" and language learning primarily aims at "learning to communicate" (Richards \& Rodgers, 1999, p. 67). Following the method, learners are expected to successfully communicate whatever situation they are in. Coming to another method, Total Physical Response is also applied through "the coordination of speech and action" that teaches foreign languages "through physical (motor) activity" (Richards \& Rodgers, 1999, p. 87). The Silent Way, therefore, "is the name of a method of language teaching devised by Caleb Gattegno... an approach to the teaching of initial reading in which sounds are coded by specific colors" (Richards \& Rodgers, 1999, p. 99).

\section{DEFINING INTERDISCIPLINARY STUDIES}

Interdisciplinary studies refer to a study method that establishes connection among different study areas. The most significant contribution of interdisciplinary studies is "to relate the particular to the whole by drawing on multiple disciplinary perspectives that are relevant to specific problem or question" (Repko \& Szostak, 2017, p. 50). Therefore, establishing a focus, an interdisciplinary method encourages learners to combine multiple perspectives at a single place. This conclusively results in attributing multidimensional thinking and learning capacity to the learners. As the learners undergo "a variety of exercises" "with a thematic and topical focus," they develop an understanding of diverse disciplines integrated into one (Szostak, 2017).

\section{AN INTERDISCIPLINARY ENGLISH LANGUAGE CLASSROOM}

Content-based language teaching classroom is not a new phenomenon. Such practice is claimed to achieve the goal of language proficiency through shifting focus from the learning of language to the learning of the subject matter (Amiri \& Fatemi, 2014). The writers also believe that content-based language learning creates an authentic, meaningful academic context to accelerate the speed of language learning (Amiri \& Fatemi, 2014). However, interdisciplinary approach to language teaching can be applied in two ways in Bangladesh's language classroom - it can be assimilated into any existing disciplines and in other way, learning from other disciplines in existing curriculum can be conducted through the medium of English language. To evaluate the appropriateness of creating an interdisciplinary English language classroom, the study here has essayed the Grammar Translation 
Method and Communicative Language Teaching particularly as these two are mainly prominent in English language classrooms of Bangladesh.

\subsection{GTM in Interdisciplinary Format}

The GTM is considered to be the oldest and traditional method of learning a language. This method is primarily based on the assumption that written form of the language is more important than the oral form and violation of grammatical structures and lexicon of a language can damage the purity of it substantially (Karakaş, 2019, p. 12). Therefore, the method emphasizes the study of "structures and lexicon," "grammar rules," "vocabulary memorization," "written translations into and out of the target language" (Karakaş, 2019, p. 12). However, the study here has believed that such traditional methods of learning a language can be merged with any mainstream discipline, for example, History, to save time and effort on the parts of the learners. Here two classic activities of the GTM have been illustrated and showed subsequently how these can be combined with History discipline.

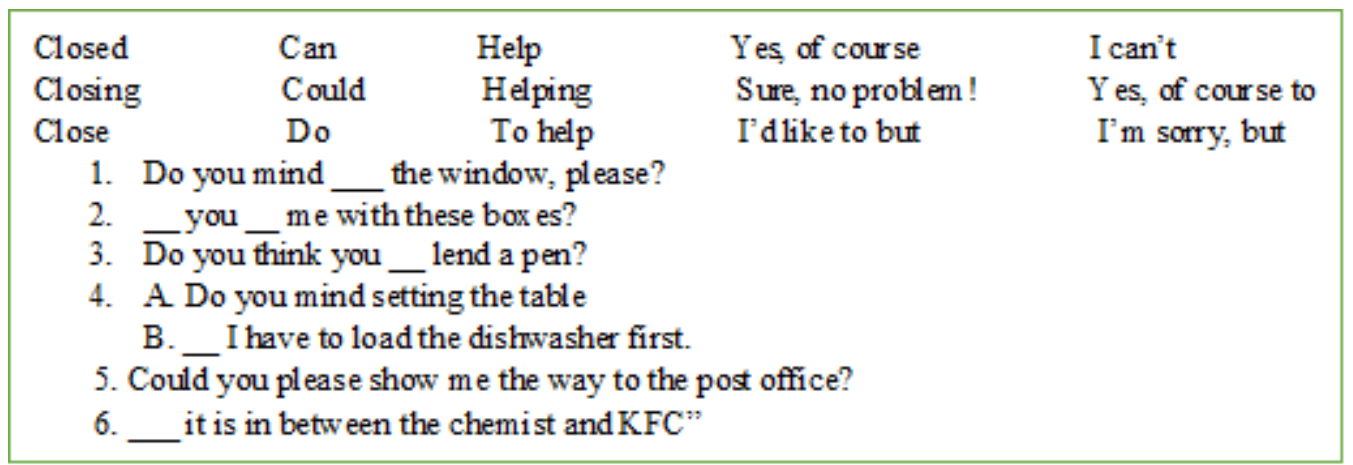

Figure1: A traditional activity of GTM (Karakaş, 2019, p. 15)

The figure that has been illustrated here shows a fill-in-the-blank example and it requires choosing the appropriate word for the blanks. The examples given here are chosen arbitrarily, not following any contextual situation. However, the same examples can be merged with any discipline - for the sake of better understanding, the discipline of History is, for instance, to be combined with language activities. To reach this end, an example activity can be to give the learners a task on reviewing the history of ethnic people living in Bangladesh before the class begins. The review is supposed to focus on the ethnic origin, lifestyle, economy, culture, community etcetera. Therefore, the abovementioned activity can be extended to accommodate both history and language. The following figure shows how this end can be achieved.

Task 1 : Choose appropriate words from the list to fill in the blanks and answer the questions:
Prefer Weave Compare
Preferring Weaving Comparison
a. Which indigenous community in Bangladesh
b. Why do they clothes for themselves?
c. How would you like to establish a buying them? between different ethnic communities?

Task 2: Place appropriate words in the blanks and answer the questions:
a. What does the economy of the ethnic people on?
b. How does their culture __significantly from non-ethnic people?
c. Write an _ essay on the lifestyle of the ethnic people.

Figure2: An interdisciplinary attempt to merge language activity with disciplinary tasks

Figure 2 connects language activities with questions from the discipline of History. The task requires much brainstorming on the part of the learners as they have to first choose the appropriate option to make a meaningful question and afterwards, they need to answer those from their acquired knowledge. This way the task of combining language activity with question from selected History discipline sees a successful completion.

Another such example of transforming a language activity into an interdisciplinary one has been taken from Basics of ELT. 
Have/has to in interrogatives/affirmatives/negatives

A. Does Elif Eslem have to make her bed?

B. No, she doesn't.

A. Does Elif Eslem have to post the letters?

B. Yes, she does.

A. Do Ali Kerem and Elif Eslem have to get up early on Sundays?

B. No. thev don't have to get un earlv on Sundavs / Yes. thev have to get un earlv on Sundavs

Figure3: Sample sentences with modal verbs of obligation (Karakaş, 2019, p. 17)

The figure above shows how questions using have/has need to be posed and how to answer those. The same questions can be formulated in an interdisciplinary way using the same discipline of History. From the aforementioned topics regarding the ethnic community in Figure 2, an interdisciplinary question format can be set to meet both ends - linguistic and historical.

Task: Make yesino, have/has, WH questions using the underlined words and explain those words:
A. The Chakmas depend on the ihum cultivation.
B. The Tripuras speak the Kokborok language.
C. The Mro people have originated from Chattogram hills.

Figure4: An interdisciplinary way to make sentence and provide learned information

The sentences in the box are plain statements out of which the learners need to formulate three types of questions. Later, they will be asked to explain the underlined words about which the learners need to have prior preparation. Their preparation, therefore, is derived from the discipline of History.

\subsection{CLT in Interdisciplinary Format}

From the word communicative, it can be discerned that the purpose of CLT is to strengthen communicative competence among the learners. A good many number of theorists have promoted this approach as effective communication is necessary in each and every sector of human life. While Henry Widdowson proposes the purpose of Communicative learning as a relationship between linguistic systems and their communicative values in text and discourse, Canale and Swaine advocate four types of competence acquired in such language learning environment - grammatical, sociolinguistic, discourse and strategic (Richards \& Rodgers, 1999, p. 71). Deviating the focus from theory to practices applied in communicative language classroom - it is widely known how a communicative language classroom uses a variety of exercises including creating a situation, role play, language games to sharpen communicative competence that can be grouped under "text-based," "task-based" and "realia" categories (Richards \& Rodgers, 1999, p. 79). Therefore, in foreign language classroom, being engaged in diverse activities, the learner develops conversational competence, vocabularies, knowledge and skill about a language. Integrating an interdisciplinary approach into this existing language learning practice can be multifunctional as it can contribute to both language competence and disciplinary knowledge. To illustrate how interdisciplinary method can be incorporated into Communicative English language classroom two examples of activities Information Gap Activity and Jigsaw Activity - have been taken from Jack C. Richards (2006).

\subsubsection{Information Gap Activity}

Students practice a role play in pairs. One student is given the information she/he needs to play the part of a clerk in the railway station information booth and has information on train departures, prices etc. The other needs to obtain information on departure time, prices etc. They role-play the interaction without looking at each other's cue cards (Richards, 2006, p.18).

This activity of creating a situation where participants need to share information with each other develops conversational competence. Therefore, for instance, the interdisciplinary method has been formed combining the discipline of History with English language and the students are asked beforehand to have an in-depth read of Railway system of Bangladesh, its changes and evolutions. The same abovementioned situation is given to accomplish primary objective of situational conversation, but the instructor asks the learners to lengthen the conversation reflecting on the history and evolution of Railway transport system of the country - resultantly, a learner achieves two goals: earning of conversational capacity and gaining knowledge about the history of Railway system of Bangladesh. 


\subsubsection{Jigsaw Activity}

Jack C. Richanrds demonstrates how this activity works:

Typically, the class is divided into groups and each group has part of the information needed to complete an activity. The class must fit the pieces together to complete the whole. In so doing, they must use their language resources to communicate meaningfully and so take part in meaningful communication practice (Richards, 2006, p. 19).

Therefore, in interdisciplinary study model, the procedure will remain same, but there might be little beforehand preparation. As information is required to be pieced together, learners might take preparation regarding the information. To make this point more specific, again this method can be merged with History discipline. If the learners are asked to get a detail knowledge about the history of the Liberation War of Bangladesh, in the class they can be given specific year or incident to further elaborate on what happens at the mentioned time. Richards demonstrates the procedure practically how the teacher divides a narrative and each student comes to hear part of it, the students therefore move around and listen to read-aloud section and finally they try to place the whole story together (Richards, 2006, p. 19). If the procedure goes interdisciplinary, the same activities can be accomplished with the learners' who would have a prior knowledge about the narrative, but the presentation of it depends on the instructor. For example, the instructor can give the name of the date and year - the $25^{\text {th }}$ March, 1971 - the learners then are to explain what exactly happens on the date. Similarly, the instructor can mention the word Guerrilla and ask the students to describe the relation of the word with Bangladesh's Liberation War. This way the learners can have a minute knowledge about a significant history of the country and develop their skill of linguistic presentation along.

\section{Discussion AND ANALYSIS}

The activities illustrated above show a simple combination of History and English language activities. These two disciplines are not connected to each other, but every discipline requires language to manifest itself. Therefore, uniting language with any other discipline might contribute to the attainment of discipline-specific terminology as well as it can sharpen language skill in a multiple way. Most importantly, in a country such as Bangladesh, where a large amount of money and effort is accosted for gaining expertise in English language, combining it with other disciplines in some cases can save the country from such extravagance. However, changing the entire educational curriculum at a time to introduce interdisciplinary education can be burdensome. Therefore, the study here recommends to introduce it limitedly at the beginning which, if proven effective, can be expanded gradually.

\section{CONCLUSION}

Bangladesh is a developing country that, to interact with the outside world, needs a common medium of language and English has assumed this status because of its imperialistic history worldwide. In spite of being liberated from foreign domination, the legacy of British rule in this land and present world's dependence on English as an international language, the country has introduced English language teaching that applies a number of approaches and methods to earn its end. However, such large scale emphasis on English language learning compels the learners to spend a long period of their life on attending classes, courses and training that, at the same time, draws a huge sum of money. To reduce such expenditure and effort, the study has tried to show a way that combines other disciplines with English language activities. It is to be mentioned that executing the plan of creating an interdisciplinary curriculum needs further assessment, research and experiment, but the study here suggests to introduce it narrowly at any level of education at first to evaluate the feasibility of addressing such system in Bangladesh.

\section{REFERENCES}

[1] Lida, Y. (2007). Interdisciplinary Curriculum for Teaching English as a Foreign Language: Cultural Bridge to Improve International Communication. Retrieved From https://pdfssemanticscholar.org/83c3/ 751863d57b285ee1574e47b2a7de756c2b6b.pdf

[2] Rahman, M. M., Islam, M. S., Karim, A., Chowdhury, T. A., Rahman, M. M., Seraj, P. M. I., \& Singh, M. K. M. (2019). English language teaching in Bangladesh today: Issues, outcomes and implication. Language Teaching in Asia, 9.9.DOI: 10.1186/s40468-019- 0085-8 
[3] Hamid, M. O. \& Erling, J. E. (2016). English-in-Education Policy and Planning in Bangladesh: A Critical Examination. English Language Education Policy in Asia. DOI: 10.1007/978-3-319-22464-0_2

[4] Chowdhury, R. \& Huq, A. (2014). Language wars: English education policy and practice in Bangladesh. Multilingual Education, 4:21. doi:10.1186/s13616 014-0021-2.

[5] Rahman, M. M. \& Pandian, A. (2018). A Critical Investigation of English Language Teaching in Bangladesh. English Today, 34 (3). doi:10.1017/S026607841700061X

[6] Mahapatra, S. (2014). An Interdisciplinary Approach to Teaching Academic Speaking Skills: An Experiment with Engineering Students. FORTELL, (28). Retrieved From https://www.researchgate.net/ publication/316692502_An_Interdisciplinary_Approach_toTeaching_Academic_Speaking_Skills_An_Ex periment_with_Engineering_Students

[7] Lee, C. (2008). Interdisciplinary collaboration in English language teaching Some observations from subject teachers' reflections. Reflections on English Language Teaching, 7(2). Retrieved from https://pdfs. semanticscholarorg/9e9d/ec626b595d2f3ee1fe0b1c37f11ebfc8b6b1.pdf

[8] Brown, H. D. (2000). Language, Learning and Teaching. Principles of Language Learning and Teaching ( $4^{\text {th }}$ Edition) (pp. 1-19). NY: Parson Education.

[9] Richards, C. J. \& Rodgers, S. T. (1999). A brief history of language teaching. Approaches and Methods in Language Teaching (pp. 1-13). USA: Cambridge University Press.

[10] Richards, C. J. \& Rodgers, S. T. (1999). The Oral Approach and Situational Language Teaching. Approaches and Methods in Language Teaching (pp. 31-43). USA: Cambridge University Press.

[11] Richards, C. J. \& Rodgers, S. T. (1999). The Audiolingual Method. Approaches and Methods in Language Teaching (pp. 44-63). USA: Cambridge University Press.

[12] Richards, C. J. \& Rodgers, S. T. (1999). Communicative Language Teaching. Approaches and Methods in Language Teaching (pp. 64-86). USA: Cambridge University Press.

[13] Richards, C. J. \& Rodgers, S. T. (1999). Total Physical Response. Approaches and Methods in Language Teaching (pp. 87-98). USA: Cambridge University Press.

[14] Richards, C. J. \& Rodgers, S. T. (1999). The Silent Way. Approaches and Method in Language Teaching (pp. 99-112). USA: Cambridge University Press.

[15] Repko, F. A. \& Szostak, R. (2017). Interdisciplinary Studies in Real World. Introduction to Interdisciplinary Studies ( $2^{\text {nd }}$ Edition) (pp. 46-63). USA: Sage Publications.

[16] Szostak, R. (2017). How and Why to teach Interdisciplinary Research Practice. Journal of Research Practice, 3(2). Retrieved from https://www.researchgate.net/publication/26492434_How_and_Why_ to_Teach_Interdisciplinary_Research_Practice

[17] Amiri, M. \& Fatemi, A. H. (2014). The Impact of Content-Based Instruction on Students' Achievement in ESP Courses and Their Language Learning Orientation. Theory and Practice in Language Studies, 4(10). DOI: $10.4304 /$ tpls.4.10.21572167

[18] Karakaş, A. (2019). Grammar Translation Method. In Yaman, Ismail, EKMEKÇİ, Emrah, Senal, Mufit (Eds.), Basics of ELT (pp. 10-31). Blackswan Publishing House.

[19] Richards, C. J. (2006). Classroom Activities in Communicative Language Teaching. Communicative Language Teaching Today (pp. 14-35). USA: Cambridge University Press.

\section{AUTHOR's BIOGRAPHY}

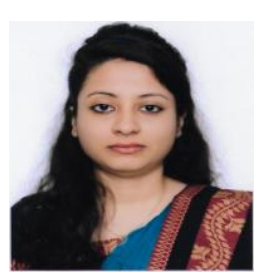

Barnali Talukder has been working as Lecturer in English, Faculty of Arts \& Humanities, University of Chittagong, Chattogram, Bangladesh, since 2018. She completed her BA (Honors) in English in 2013 and MA in English Literature in 2014 from University of Dhaka, Bangladesh. Besides working as an English language instructor at the university, she has an interest in cultural studies.

Citation: Barnali Talukder. Introducing Interdisciplinary English Language Classroom in Bangladesh: An Assessment. "International Journal on Studies in English Language and Literature (IJSELL), vol 7, no. 12, 2019, pp. 63-69. doi: http://dx.doi.org/10.20431/2347-3134.0712005.

Copyright: (C) 2019 Authors. This is an open-access article distributed under the terms of the Creative Commons Attribution License, which permits unrestricted use, distribution, and reproduction in any medium, provided the original author and source are credited. 